\title{
openheart Efficacy and follow-up of transcatheter aortic valve implantation in patients with radiation-induced aortic stenosis
}

\author{
Marina Dijos, Amélie Reynaud, Lionel Leroux, Patricia Réant, Claire Cornolle, \\ Raymond Roudaut, Pierre Dos Santos, Stéphane Lafitte
}

To cite: Dijos M, Reynaud A, Leroux L, et al. Efficacy and follow-up of transcatheter aortic valve implantation in patients with radiationinduced aortic stenosis. Open Heart 2015;2:e000252. doi:10.1136/openhrt-2015000252

Received 12 February 2015 Revised 22 June 2015 Accepted 31 July 2015

\section{CrossMark}

\section{Valvular Disease Department and Echocardiography Laboratory, Haut-Lévêque Bordeaux University Hospital-CIC0005-France, Pessac, France}

Correspondence to Dr Stéphane Lafitte; stephane.lafitte@chubordeaux.fr

\section{ABSTRACT}

Objective: To investigate transcatheter aortic valve implantation (TAVI) feasibility, effectiveness and safety in radiation-induced aortic valve stenosis cases.

Methods: 198 consecutive patients referred for TAVI were prospectively enrolled. They were divided into two groups: patients with a history of chest radiation therapy with suspected radiation-induced valvular disease (RXT) and others with suspected degenerative aortic valve stenosis (NRXT). Procedural, early and mid-term clinical outcomes were compared.

Results: Of the 198 patients enrolled in our study, $9.6 \%$ qualified for inclusion in the RXT group. A comparison of baseline characteristics revealed that patients with RXT were younger than patients with NRXT (68.3 vs 82.5 years; $p<0.05$ ) and exhibited a lower surgical risk score (Euroscore: $7.1 \%$ vs $21.8 \%$ $\mathrm{p}<0.05)$ and a higher frequency of hostile thorax and porcelain aorta (52.6\% vs $28.5 \%$; $p<0.05 ; 63.2 \%$ vs $10.6 \% ; p<0.05$, respectively). In both groups, the implantation success rate was high and the 30-day safety end point acceptable (RXT: $94.7 \%$ and $83.3 \%$; NRXT: $93.9 \%$ and $75.6 \%$, respectively). At 6 months, overall mortality was significantly lower in the RXT group ( $0 \%$ vs $18 \% ; p=0.048$ ).

Conclusions: In patients suffering from radiationinduced aortic valve stenosis and contraindicated for surgery, TAVI is a promising approach, with high feasibility, acceptable risk, low mortality and high clinical effectiveness at mid-term follow-up.

\section{INTRODUCTION}

Using radiation therapy in thoracic malignancy management has led to significant improvements in survival. However, radiationinduced cardiovascular diseases have been reported to manifest decades after therapy and now represent the most common nonmalignant cause of death in survivors of radiation-treated cancer. ${ }^{1}$

Both disease incidence and severity increase with higher radiation doses, larger exposed volumes, younger age at time of exposure and greater time elapsed since treatment. Despite the safety advances achieved

\section{KEY MESSAGES}

What is already known about this subject?

- This is the first study to focus on the subgroup of patients with transcatheter aortic valve implantation (TAVI) who present with radiationinduced aortic stenosis.

What does this study add?

- We compared this subgroup of patients with conventional patients with TAVI in order to identify a specific profile in immediate results and during the 6 months follow-up. As a main finding, we observed a reduced mortality rate in the patients with radiation-induced aortic stenosis at 6 months.

How might this impact on clinical practice?

- The impact of this study could be a better selection of this subgroup of patients for TAVI.

over the past decades in radiation therapy, patients with Hodgkin's lymphoma or left breast, lung, oesophageal or gastric cancer still receive as standard either a high dose of radiation to a small part of the heart or a low dose to the whole heart. ${ }^{2}$

Manifestations of radiation-induced heart disease include accelerated atherosclerosis, pericardial and myocardial fibrosis, conduction abnormalities and cardiac valve damage. ${ }^{2-7}$

Radiation-induced valvular diseases affect approximately $6-15 \%$ of patients exposed to mediastinal radiation. ${ }^{8}$ While aortic or mitral valvular regurgitation is the more commonly seen dysfunction, aortic stenosis is typically the main reason motivating surgical options. On average, valve lesions are diagnosed 11.5 years after radiation therapy, and symptoms occur 5 years later. $^{9}$ In comparison to a normal matched population, patients with mediastinal radiation have been reported to exhibit increased risk of requiring valve surgery, with a standard incidence ratio of 9.2. ${ }^{10}$ 
Nevertheless, aortic or mitral valve replacement is associated with myocardial dysfunction, severe coronary artery disease, high frequency of extensively calcified ascending aorta, mediastinal fibrosis, lung fibrosis and chest wall deformation. This intervention may therefore lead to high surgical mortality, even in young patients, whether associated with coronary artery bypass or not. For this reason, some of these patients are contraindicated for surgery, which is associated with very poor prognosis. $^{11} 12$

Transcatheter aortic valve implantation (TAVI) has recently emerged as a promising alternative to surgical aortic valve replacement for high-risk patients with severe symptomatic aortic stenosis. ${ }^{12}$ In a little over a decade after the first implantation performed by Cribier et al, more than 50000 patients have been treated worldwide by TAVI. This technique has been performed mostly in older frail patients suffering from symptomatic degenerative aortic valve stenosis with comorbidities. Yet it also appears to be an interesting alternative to surgical aortic valve replacement in younger patients presenting with radiation-induced aortic valve stenosis and hostile thorax who are at-risk candidates for conventional surgery. The percutaneous approach (transfemoral, subclavian, transcarotid or transapical) may, in fact, overcome issues of extensively calcified ascending aorta, mediastinal fibrosis, pericardial calcification and chest wall deformation. ${ }^{13}$

Over the past few years, several encouraging case reports have been published concerning TAVI in patients with radiation-induced aortic stenosis.

Our study aimed to make the first ever comparison of the procedural results, clinical symptom status and early to mid-term outcomes of TAVI between patients with radiation-induced aortic stenosis and those with degenerative aortic stenosis.

\section{METHODS}

\section{Study population}

Consecutive patients diagnosed with severe symptomatic aortic valve stenosis and considered unsuitable for conventional surgery, referred for TAVI between January 2011 and January 2013 at the Cardiologic University Hospital of Bordeaux, were prospectively enrolled in the study. Severe aortic valve stenosis was defined as an aortic valve area $<1 \mathrm{~cm}^{2}$, a mean aortic valve gradient $\geq 40 \mathrm{~mm} \mathrm{Hg}$ or a peak aortic jet velocity $\geq 4 \mathrm{~m} / \mathrm{s}$, as determined by echocardiography following the recommendations of the American Society of Echocardiography. ${ }^{14}$ Patients with a low-flow, low-gradient aortic stenosis could be included in the study. Each patient was first evaluated by a heart team, including a surgeon, cardiologist and anaesthesiologist. Symptoms, medical history, comorbidities, surgical score, thorax analysis, life expectancy, level of frailty and prescreening examinations (echocardiography, aortic CT scan and coronary angiography) were assessed by the heart team. In accordance with American and European guidelines, ${ }^{15}{ }^{16}$ the heart team selected patients with severe and symptomatic aortic valve stenosis, along with high surgical risk scores (logistic Euroscore $>20 \%$ or Society of Thoracic Surgeons (STS) score $>10 \%)^{17} 18$ for TAVI, as well as those exhibiting other risk factors not captured by the risk scores, such as hostile thorax, porcelain aorta, severe liver disease or high degree of frailty. Diagnoses of porcelain aorta and hostile chest were established according to the Valve Academic Research Consortium-2 consensus document. ${ }^{19}$ Furthermore, on the basis of prescreening results, patients had to have a life expectancy exceeding 1 year and anatomical features compatible with TAVI.

The study population was divided into two groups:

- The first group included radiation-induced valvular disease cases (RXT), consisting of patients who had previously undergone mediastinal or left-chest-wall radiation treatment for cancer more than 10 years before inclusion. Reasons for radiation therapy and year of treatment were recorded.

- The second group included non-radiation-induced valvular disease cases (NRXT), consisting of patients who had never undergone thoracic radiation therapy presenting with suspected degenerative aortic valve stenosis.

\section{TAVI procedure}

The TAVI procedure has previously been reported in detail. ${ }^{12} 15{ }^{20}$ In brief, the procedure consists in the following: the preferred access route was the femoral artery; other access sites (subclavian or carotid artery, transaortic, or transapical) were considered when femoral access was not suitable due to severe femoral artery disease; the femoral artery was punctured percutaneously and closed using a suture device, while the other access sites were managed surgically. Two commercially available systems were used: a self-expandable prosthesis, namely the Medtronic CoreValve Revalving System (Medtronic, Minneapolis, Minnesota, USA); a balloon-expandable prosthesis, the Edwards SAPIEN valve (Edwards Lifesciences, Irvine, California, USA). All patients provided written informed consent before the TAVI procedure.

\section{Study end points}

The primary end points were:

- Device implantation success: composite end point defined as the absence of procedural mortality, positioning of a single prosthetic heart valve into the correct anatomical location, and appropriate prosthetic valve function;

- Thirty-day combined safety: composite end point defined as the absence of all-cause mortality, stroke (disabling and non-disabling), life-threatening bleeding, acute kidney damage, coronary artery obstruction requiring surgery, major vascular complication or valve-related dysfunction requiring repeat procedure; 
- Six-month cardiovascular and overall mortality;

- Six-month clinical efficacy: composite end point defined as the absence of all-cause mortality, stroke (disabling and non-disabling), hospitalisation for valve-related symptoms or worsening congestive heart failure, New York Heart Association (NYHA) Class III or IV, or valve-related dysfunction.

The secondary end points were procedural complications:

- Thirty-day cardiovascular and overall mortality;

- Bleeding complications classified as 'life-threatening', 'major' or 'minor';

- Vascular complications classified as 'major' or 'minor';

- All strokes (disabling and non-disabling);

- Acute kidney injury;

- Conduction disturbances leading to pacemaker implantation;

- Six-month performance of the bioprosthesis, as assessed by echocardiography (mean gradient, aortic valve area and presence of aortic valve regurgitation). Composite end points and procedural complications were defined in accordance with Valve Academic Research Consortium 2 (VARC2) criteria. $^{19}$

\section{Data collection}

All data selected for analysis in this study were obtained from patient medical files. These included medical history, baseline clinical findings, patient characteristics, coronary angiography findings, as well as aortic CT, transthoracic or transoesophageal echocardiography findings, and periprocedural parameters, such as bioprosthesis type, access route and adverse events. The data also included 30-day and 6-month patient survival, clinical status and echocardiographic findings. This information was obtained and recorded in each patient's medical file during dedicated consultations at 30 days and 6 months, or by telephone if the patient could not attend consultations. Clinical symptom status was evaluated at baseline using the NYHA classification system for all patients. The survivors were also assessed 6 months after TAVI, during the consultation. Each patient underwent a transthoracic echocardiography at baseline, prior to discharge, and at 6-month follow-up. Echocardiographic examinations were all performed in our echocardiography laboratory by experienced sonographers, with the results stored on digital workstations (EchoPAC PC, GE Vingmed Ultrasound SA). Left-ventricular volumes and ejection fraction were calculated using the biplane disk method (modified Simpson's rule). The degree of aortic valve stenosis was evaluated on the basis of the mean aortic valve gradient, calculated using continuous-wave Doppler and a continuity equation-based assessment of the aortic valve area. The degree of calcification of the aortic valve was scored as follows: 1 , no calcification; 2 , mildly calcified (small isolated spots); 3, moderately calcified (multiple larger spots) and 4, heavily calcified (extensive thickening and calcification of all cusps). ${ }^{21}$
The severity of preprocedural aortic valve regurgitation (grades 0-4) and preprocedural or postprocedural mitral regurgitation (grades 0-4) was assessed according to current guidelines and based on the presence of mitral valve stenosis. ${ }^{14} 22-24$ The degree of postprocedural aortic valve regurgitation (grades $0-4$ ), including central or paravalvular leak, was assessed according to the VARC2 document recommendations. ${ }^{19}$

\section{Statistical analysis}

All statistical analyses were carried out using the Statel software (AdScience, Paris, France). Continuous variables were expressed as mean $\pm \mathrm{SD}$, and categorical data values were expressed as percentages. Comparisons between the two groups were performed using the unpaired Student t test, Mann-Whitney test, $\chi^{2}$ test or Fisher's exact test as appropriate. All statistical tests were two-sided, and a $\mathrm{p}$ value $<0.05$ was considered statistically significant.

\section{RESULTS}

\section{Patient baseline characteristics}

Of the 202 patients accepted for TAVI procedure between January 2011 and January 2013, four patients with a history of radiation therapy were excluded: two had undergone radiation therapy less than 10 years ago while the remaining two had received right chest radiation therapy for right breast cancer.

Thus, 198 patients were enrolled in our study. 19 patients (9.6\%) were assigned to the radiationinduced valvular disease (RXT) group and $179(90.4 \%)$ to the non-radiation-induced valvular disease (NRXT) group. Hodgkin's lymphoma was the most common reason for radiation therapy $(42.5 \%)$, followed by left breast cancer $(36.8 \%)$, and then lung cancer $(10.5 \%)$. Mean age was lower in the RXT group than in the NRXT group ( 68.3 vs 82.5 years; $p=0.00001$ ) and traditional cardiovascular risk factors were less represented in the RXT group, with lower proportions of hypertension $(47.3 \%$ vs $77.6 \%$; $\mathrm{p}=0.0095)$, diabetes mellitus $(5.3 \%$ vs $31.3 \%$; $\mathrm{p}=0.017)$ and peripheral artery disease $(10.5 \%$ vs $33.5 \%$; $\mathrm{p}=0.04$ ) observed. Renal function was significantly better in the RXT group, with an estimated glomerular filtration rate (according to the Cockcroft-Gault formula) of 107.2 vs $52.4 \mathrm{~mL} / \mathrm{mn}$ in the NRXT group ( $\mathrm{p}=0.00001$ ).

The mean logistic Euroscore was low in the RXT group $(7.1 \% \pm 4.5 \%)$, whereas it exceeded $20 \%$ in the NRXT group $(21.8 \% \pm 12.5 \%)$, resulting in statistical difference between the two groups $(\mathrm{p}=0.00001)$. Mean Euroscore 2 was $2.7 \%$ in the RXT group and $10.3 \%$ in the NRXT group.

On the other hand, hostile thorax and porcelain aorta were more common in the RXT group $(52.6 \%$ vs $28.5 \%$; $\mathrm{p}=0.03 ; 63.2 \%$ vs $10.6 \% ; \mathrm{p}=0.00001$, respectively). Baseline patient characteristics have been listed in table 1 .

With regard to echocardiographic findings before TAVI, there was no statistical difference noted between the RXT and NRXT groups in terms of ejection fraction $(57 \% \pm 11.3 \%$ vs $53.8 \% \pm 14.4 \%$; $\mathrm{p}=0.36)$, mean aortic 
Table 1 Baseline patient characteristics

\begin{tabular}{|c|c|c|c|c|}
\hline Variable & $\begin{array}{l}\text { Total } \\
(n=198)\end{array}$ & $\begin{array}{l}\text { RXT } \\
(n=19)\end{array}$ & $\begin{array}{l}\text { NRXT } \\
(n=179)\end{array}$ & p Value \\
\hline Age (years) & $81.1 \pm 8.4$ & $68.3 \pm 11.7$ & $82.5 \pm 6.6$ & $<0.00001$ \\
\hline Women & $90(45.4 \%)$ & $12(63.2 \%)$ & $78(43.6 \%)$ & 0.1 \\
\hline Body mass index $\left(\mathrm{kg} / \mathrm{m}^{2}\right)$ & $27 \pm 5.6$ & $25.9 \pm 5.1$ & $27.1 \pm 5.7$ & 0.37 \\
\hline NYHA 3 or $4(\%)$ & $169(85.3 \%)$ & $14(73.6 \%)$ & $155(86.6 \%)$ & 0.17 \\
\hline Peripheral artery disease & $62(31.3 \%)$ & $2(10.5 \%)$ & $60(33.5 \%)$ & 0.04 \\
\hline Previous heart failure & $105(53.0 \%)$ & $8(42.1 \%)$ & $97(54.1 \%)$ & 0.32 \\
\hline Coronary artery disease & $113(57.1 \%)$ & $9(47.3 \%)$ & $104(58.1 \%)$ & 0.37 \\
\hline Previous cerebrovascular event & $11(5.6 \%)$ & $0(0 \%)$ & $11(6.1 \%)$ & 0.6 \\
\hline Diabetes mellitus & $57(28.8 \%)$ & $1(5.3 \%)$ & $56(31.3 \%)$ & 0.017 \\
\hline Hypertension & $148(74.7 \%)$ & $9(47.3 \%)$ & $139(77.6 \%)$ & 0.0095 \\
\hline Chronic pulmonary disease & $75(37.9 \%)$ & $9(47.3 \%)$ & $66(36.9 \%)$ & 0.37 \\
\hline Logistic Euroscore (\%) & $20.3 \pm 12.7$ & $7.1 \pm 4.5$ & $21.8 \pm 12.5$ & $<0.00001$ \\
\hline $\begin{array}{l}\text { Estimated glomerular filtration rate } \\
(\mathrm{mL} / \mathrm{min}) \text { with Cockroft formula }\end{array}$ & $57.7 \pm 32.5$ & $107.2 \pm 35.2$ & $52.4 \pm 27.4$ & $<0.00001$ \\
\hline Previous cardiac surgery & $53(26.8 \%)$ & $2(10.5 \%)$ & $51(28.5 \%)$ & 0.093 \\
\hline Hostile thorax & $61(30.1 \%)$ & $10(52.6 \%)$ & $51(28.5 \%)$ & 0.03 \\
\hline Porcelain aorta & $31(15.7 \%)$ & $12(63.2 \%)$ & $19(10.6 \%)$ & $<0.00001$ \\
\hline History of atrial fibrillation & $73(36.9 \%)$ & $2(10.5 \%)$ & $71(39.7 \%)$ & 0.012 \\
\hline Pacemaker & $41(20.7 \%)$ & $4(21 \%)$ & 37 (20.6\%) & 1 \\
\hline
\end{tabular}

Values are expressed as mean \pm SD or $n(\%)$.

NRXT, non-radiation-induced valvular disease; NYHA, New York Heart Association; RXT, radiation-induced valvular disease.

valve gradient $(47.9 \pm 15.5$ vs $45.9 \pm 15.8 \mathrm{~mm} \mathrm{Hg} ; \mathrm{p}=0.92)$ or aortic valve area $\left(0.60 \pm 0.18\right.$ vs $\left.0.68 \pm 0.23 \mathrm{~cm}^{2} ; \mathrm{p}=0.22\right)$. On the other hand, mitral valve stenosis and aortic valve regurgitation were more frequently observed in the RXT group (57.9\% vs $9.5 \%$; $\mathrm{p}=0.00001$ and $47.3 \%$ vs $16.9 \%$; $\mathrm{p}=0.0038$, respectively), though no statistical difference was found concerning systolic pulmonary artery pressure (41.7 \pm 9.7 vs $38.8 \pm 13.2 \mathrm{~mm} \mathrm{Hg} ; \mathrm{p}=0.16)$.

With regard to the aortic valve calcium score, we found statistical difference between the two groups with a mean value of $2.4 \pm 0.7$ in the $\mathrm{RXT}$ group and $3.2 \pm 0.4$ in the NRXT group $(\mathrm{p}<0.0001)$.

Echographic findings at baseline have been outlined in table 2 .

\section{Procedural characteristics}

The type of bioprosthesis and distribution of access routes did not significantly differ between the two groups. The implantation success rate was high in both groups, as shown by device implantation success composite end points of $94.7 \%$ and $93.9 \%$ in the RXT and NRXT groups, respectively $(p=0.9)$. Only one device implantation failed in the RXT group due to left coronary obstruction by TAVI, requiring the procedure to be stopped. The mean duration of the procedure was $55 \pm 9 \mathrm{~min}$ in the RXT group and $59 \pm 12 \mathrm{~min}$ in the NRXT group $(\mathrm{p}=0.3)$.

Five patients from the NRXT group who were transferred to another institution were lost to follow-up.

Table 2 Baseline echographic variables

\begin{tabular}{|c|c|c|c|c|}
\hline Variable & $\begin{array}{l}\text { Total } \\
(n=198)\end{array}$ & $\begin{array}{l}R X T \\
(n=19)\end{array}$ & $\begin{array}{l}\text { NRXT } \\
(n=179)\end{array}$ & p Value \\
\hline Ejection fraction (\%) & $54.1 \pm 14.2$ & $57 \pm 11.3$ & $53.8 \pm 14.4$ & 0.36 \\
\hline Ejection fraction $<35 \%$ & $24(12.1 \%)$ & $1(5.3 \%)$ & $23(12.8 \%)$ & 0.46 \\
\hline Aortic valve area $\left(\mathrm{cm}^{2}\right)$ & $0.66 \pm 0.18$ & $0.60 \pm 0.18$ & $0.66 \pm 0.23$ & 0.22 \\
\hline Mean gradient $(\mathrm{mm} \mathrm{Hg})$ & $46.1 \pm 15.7$ & $47.9 \pm 15.5$ & $45.9 \pm 15.8$ & 0.92 \\
\hline Aortic regurgitation $\geq 2$ & $39(19.8 \%)$ & $9(47.3 \%)$ & $30(16.9 \%)$ & 0.0038 \\
\hline Mitral regurgitation $\geq 2$ & $50(25.6 \%)$ & $3(15.7 \%)$ & $47(26.7 \%)$ & 0.41 \\
\hline Mitral stenosis & $28(14.2 \%)$ & $11(57.9 \%)$ & $17(9.5 \%)$ & $<0.00001$ \\
\hline Pulmonary artery pressure (mm Hg) & $39.1 \pm 12.9$ & $41.7 \pm 9.7$ & $38.8 \pm 13.2$ & 0.16 \\
\hline Pulmonary artery pressure $\geq 50 \mathrm{~mm} \mathrm{Hg}$ & $41(20.7 \%)$ & $6(31.6 \%)$ & $35(19.5 \%)$ & 0.24 \\
\hline
\end{tabular}

Values are expressed as mean \pm SD or $n(\%)$.

NRXT, non-radiation-induced valvular disease; RXT, radiation-induced valvular disease. 
In terms of early complications, no statistical difference was noted between the two groups. The 30-day combined safety end point was, in fact, $83.3 \%$ in the RXT group and $75.6 \%$ in the NRXT group $(\mathrm{p}=0.57)$. Vascular and bleeding complications did not significantly differ. The following two major vascular complications occurred in the RXT group: a fistula between the aorta and right ventricle in one patient and a left carotid artery obstruction requiring a right-to-left carotid bypass in the other.

None of the patients in the RXT group presented with a disabling or non-disabling stroke, while 10 (5.81\%) of those in the NRXT group suffered from cerebrovascular events, though this difference did not reach statistical significance $(\mathrm{p}=0.6)$. Procedural characteristics have been listed in table 3 .

\section{Six-month follow-up}

All in all, 10 patients from the NRXT group were lost to follow-up at 6 months. The overall mortality at 6 months was significantly higher in the NRXT group than in the RXT group ( $18 \%$ vs $0 \%$; $\mathrm{p}=0048$ ). None of the patients in the RXT group died during follow-up. Cardiovascular mortality did not differ significantly between the two groups (RXT: 0\%, NRXT: $11.4 \%, \mathrm{p}=0.22$ ). There was a trend towards better clinical efficacy in the RXT group, as shown by the 6 -month clinical efficacy composite end point that reached $88.9 \%$ in this group, as compared with $69.5 \%$ in the NRXT group $(\mathrm{p}=0.08)$. The 6 -month follow-up results have been presented in table 3 .

Echocardiographic follow-up at 6 months revealed favourable haemodynamic results in both groups. No intravalvular or paravalvular aortic regurgitation exceeding grade 1 was observed in the RXT group, while this was reported in $9.8 \%$ of the patients in the NRXT group, with the difference not statistically significant $(\mathrm{p}=0.36)$. Echocardiographic findings at 6 months have been outlined in table 4 .

\section{DISCUSSION}

In our study, patients exhibiting radiation-induced aortic stenosis represented almost $10 \%$ of the patients referred for TAVI, equating to approximately the same proportion found in national registries. ${ }^{12} 1320$

First of all, our findings highlighted that this patient population exhibits characteristics that differ from those of patients with degenerative aortic valve stenosis. Patients with radiation-induced aortic valve stenosis do, in fact, present with less comorbidities, less cardiovascular risk factors and less peripheral vascular diseases, are younger, and their renal function is, for the greater part, unimpaired. These patients display a low logistic Euroscore that does not constitute a motivation for choosing TAVI instead of conventional surgery. This is in contrast to the population with degenerative aortic valve stenosis where a logistic Euroscore above $20 \%$ is the main reason for TAVI ( $49 \%$ of patients in our study).
Our primary reasons for choosing the percutaneous procedure in patients with RXT included the presence of a porcelain aorta for approximately two-thirds of them, or a hostile thorax (skin burns, thoracic deformation, lung fibrosis or prior coronary artery bypass) for the remaining patients. On the other hand, these two reasons only applied to $15 \%$ of patients in the NRXT group. Baseline echocardiographic findings also revealed over half of the patients with radiation-induced aortic stenosis to be suffering from mitral valve stenosis, as compared with only $10 \%$ of patients with degenerative aortic valve stenosis. Interestingly, baseline aortic valve regurgitation, as detected by echocardiography, was more frequent in the RXT group, suggesting that valvular retraction is more marked in this population.

Our study revealed that patients with radiation-induced aortic valve stenosis had lower 6-month overall mortality following TAVI than those with degenerative aortic valve stenosis. According to our interpretation, this decreased postprocedural mortality is multifactorial. First of all, it may be accounted for by more favourable baseline patient characteristics (younger patients with less comorbidities), and second by lower native valve calcifications, leading to a lower risk of paravalvular leak and stroke. With regard to the aortic valve structure itself, we hypothesised that radiation-induced aortic valve stenosis might be less calcified than degenerative stenosis. In patients with prior radiation therapy, observations made during surgery revealed that aortic valve nodular thickening and fibrosis were at least in part responsible for stenosis, whereas calcification was the main form of valvular damage in the context of degenerative aortic valve stenosis. ${ }^{25-28}$ In this sense, we have noticed in this study that the baseline echographic calcium score was lower in the RXT group. Recent studies have demonstrated that severe native valve calcifications (calcium mass score), as measured by a CT scan, were a significant predictor of a post-TAVI relevant paravalvular leak, ${ }^{29}$ and more generally of 30-day major adverse cardiovascular events and 1-year mortality. As a matter of fact, patients with severe periprocedural complications (death, acute myocardial infarction or stroke) exhibited significantly more aortic valve calcium than those without any complications. ${ }^{30}$ These studies concluded that such a parameter was extremely valuable for improving our ability to select and risk stratify candidates for TAVI. This parameter did not attain statistical significance in our study, most likely due to the small sample size of the RXT group. Nevertheless, the RXT patients suffered no postprocedural stroke, and no significant paravalvular aortic regurgitation was revealed on the 6-month echocardiography examination.

Our study also demonstrated that no specific complication appeared to be linked to the history of radiation therapy. The early postprocedural safety end point did not significantly differ between the two groups. Only one patient from the RXT group developed aortic root 
Table 3 Procedural and postprocedural results

\begin{tabular}{|c|c|c|c|c|}
\hline $\begin{array}{l}\text { Variable } \\
\text { Periprocedural }\end{array}$ & $\begin{array}{l}\text { Total } \\
(n=198)\end{array}$ & $\begin{array}{l}\mathrm{RXT} \\
(\mathrm{n}=19) \\
\end{array}$ & $\begin{array}{l}\text { NRXT } \\
(n=179)\end{array}$ & p Value \\
\hline \multicolumn{5}{|l|}{ Type of bioprosthesis } \\
\hline Medtronic corevalve & 97 (49\%) & $9(47.4 \%)$ & $88(49.2 \%)$ & 0.88 \\
\hline Edwards sapien & $98(49.5 \%)$ & $9(47.4 \%)$ & $89(49.7 \%)$ & 0.85 \\
\hline Implantation failure (no valve implanted) & $3(1.5 \%)$ & $1(5.3 \%)$ & $2(1.1 \%)$ & 0.26 \\
\hline \multicolumn{5}{|l|}{ Access route } \\
\hline Transfemoral & $153(77.3 \%)$ & $17(89.5 \%)$ & $136(76 \%)$ & 0.25 \\
\hline Transapical & 25 (12.6\%) & $1(5.3 \%)$ & $24(13.4 \%)$ & 0.48 \\
\hline Subclavian & $13(6.6 \%)$ & $1(5.3 \%)$ & $12(6.7 \%)$ & 1 \\
\hline Transaortic & $4(2.0 \%)$ & $0(0 \%)$ & $4(2.2 \%)$ & 1 \\
\hline Transcarotid & $3(1.5 \%)$ & $0(0 \%)$ & $3(1.7 \%)$ & 1 \\
\hline Device implantation success composite end point & $186(94 \%)$ & $18(94.7 \%)$ & $168(93.9 \%)$ & 0.9 \\
\hline Postprocedural- -30 days & $(n=190)$ & $(n=18)$ & $(n=172)$ & \\
\hline 30-day mortality & $20(10.5 \%)$ & $0(0 \%)$ & $20(11.6 \%)$ & 0.23 \\
\hline CV mortality & $13(6.8 \%)$ & $0(0 \%)$ & $13(7.6 \%)$ & 0.62 \\
\hline Non-CV mortality & $7(3.7 \%)$ & $0(0 \%)$ & $7(4.1 \%)$ & 1 \\
\hline Early safety composite end point & $145(76.3 \%)$ & $15(83.3 \%)$ & $130(75.6 \%)$ & 0.57 \\
\hline Stroke (all types) & $10(5.3 \%)$ & $0(0 \%)$ & $10(5.81 \%)$ & 0.6 \\
\hline Life-threatening or major bleeding & $23(12.1 \%)$ & $0(0 \%)$ & $23(13.4 \%)$ & 0.14 \\
\hline Major vascular complication & $12(6.3 \%)$ & $2(11.1 \%)$ & $10(5.8 \%)$ & 0.32 \\
\hline Acute kidney injury & $21(11.1 \%)$ & $1(5.6 \%)$ & $20(11.6 \%)$ & 0.7 \\
\hline Minor vascular complication & $17(8.9 \%)$ & $3(16.7 \%)$ & $14(8.1 \%)$ & 0.21 \\
\hline Minor bleeding & $21(11.1 \%)$ & $2(11.1 \%)$ & $19(11 \%)$ & 1 \\
\hline New pacemaker implantation & $36(18.9 \%)$ & $5(27.8 \%)$ & $31(18 \%)$ & 0.34 \\
\hline \multicolumn{5}{|l|}{ Postprocedural-6 months } \\
\hline 6-month mortality & $30 / 185(16.2 \%)$ & $0(0 \%)$ & $30 / 167(18 \%)$ & 0.048 \\
\hline CV mortality & 19/185 (10.3\%) & $0(0 \%)$ & 19/167 (11.4\%) & 0.22 \\
\hline Non-CV mortality & $11 / 185(5.9 \%)$ & $0(0 \%)$ & $11 / 167(6.6 \%)$ & 0.6 \\
\hline 6-month clinical efficacy composite end point & $132 / 185(71.3 \%)$ & $16(88.9 \%)$ & $116 / 167(69.5 \%)$ & 0.083 \\
\hline NYHA class 3 or 4 at 6 months & $23 / 155(14.8 \%)$ & $2(11.1 \%)$ & $21 / 137(15.3 \%)$ & 1 \\
\hline Rehospitalisation for valve-related symptoms & $28 / 155(18.1 \%)$ & $2(11.1 \%)$ & $26 / 137(19 \%)$ & 0.53 \\
\hline
\end{tabular}

Values are expressed as mean \pm SD or $n(\%)$.

CV, cardiovascular; NRXT, non-radiation-induced valvular disease; NYHA, New York Heart Association; RXT, radiation-induced valvular disease.

damage (aorta-right ventricle fistula), which was similar to a small aortic root dissection. This severe but rare complication is not specific to irradiated patients and may occur in any context. ${ }^{31}$

Lastly, this study proved TAVI capable of achieving high clinical effectiveness in radiation-induced valvular disease, as demonstrated by the statistically significant trend of its increased clinical efficacy observed in the RXT group compared to that of the NRXT group. Close to $90 \%$ of patients were categorised as NYHA Class 1 or 2 at 6-month follow-up, with no need for a valve-related hospitalisation. This is an interesting result, given that $73 \%$ of the patients in the RXT group also exhibited mitral valve stenosis, or at least moderate mitral valve

Table 4 Echographic findings at 6 months

\begin{tabular}{|c|c|c|c|c|}
\hline Variable & Total & RXT & NRXT & p Value \\
\hline Ejection fraction (\%) & $59.1 \pm 11.3$ & $58 \pm 12.5$ & $59.3 \pm 11.3$ & 0.67 \\
\hline Ejection fraction $<35 \%$ & $5 / 141(3.5 \%)$ & $0 / 18(0 \%)$ & $5 / 123(4.1 \%)$ & 1 \\
\hline Aortic valve area $\left(\mathrm{cm}^{2}\right)$ & $1.63 \pm 0.39$ & $1.58 \pm 0.26$ & $1.64 \pm 0.41$ & 0.77 \\
\hline Mean gradient $(\mathrm{mm} \mathrm{Hg})$ & $9.8 \pm 5.3$ & $8.9 \pm 3.9$ & $10 \pm 5.4$ & 0.55 \\
\hline Aortic regurgitation $\geq 2$ & $12 / 141(8.5 \%)$ & $0 / 18(0 \%)$ & $12 / 123(9.8 \%)$ & 0.36 \\
\hline Mitral regurgitation $\geq 2$ & $27 / 141(19.1 \%)$ & $2 / 18(11.1 \%)$ & $25 / 123(20.3 \%)$ & 0.53 \\
\hline Mitral stenosis & $24 / 141(17.0 \%)$ & $10 / 18(55.6 \%)$ & $14 / 123(11.4 \%)$ & 0.00006 \\
\hline Pulmonary artery pressure $(\mathrm{mm} \mathrm{Hg})$ & $39.2 \pm 13.1$ & $36.8 \pm 11.4$ & $40.2 \pm 14.5$ & 0.44 \\
\hline Pulmonary artery pressure $\geq 50 \mathrm{~mm} \mathrm{Hg}$ & $31 / 138(22.5 \%)$ & 4/18 (22.2\%) & $27 / 120(22.5 \%)$ & 1 \\
\hline
\end{tabular}


regurgitation associated with aortic valve stenosis. The clinical impact of associated mitral valve disease seems to be lower than that of advanced age and comorbidities.

\section{Study limitations}

The main limitation of our study was the small size of the RXT group compared with the population of implanted patients. A larger multicentre study, along with a longer follow-up, would be necessary to confirm our results. Nevertheless, we obtained significant results regarding 6-month mortality.

Another limitation was the difficulty we experienced in unequivocally correlating aortic valve stenosis with prior radiation exposure for patients in the RXT group. As it is, there were no truly specific echocardiographic signs, and we can only assume that aortic valve stenosis was linked to radiation damage.

An additional limitation was that the CT scan calcium score could not be measured at the end of the study, as the required specific CT imaging was not performed systematically. Further investigations would be necessary to compare the CT scan calcium score between radiation-induced and degenerative aortic valve stenosis.

\section{CONCLUSION}

In patients suffering from radiation-induced aortic valve stenosis and contraindicated for conventional surgery, TAVI appears to be a highly promising procedure showing high feasibility, no specific early complications, favourable postprocedural haemodynamic results evaluated by echocardiography, and lower mid-term mortality compared with patients with degenerative aortic valve stenosis. TAVI demonstrated high clinical effectiveness, with more than $85 \%$ of patients categorised as NYHA class 1 or 2 at 6 months and with no need for valve-related rehospitalisation.

Contributors MD contributed to data analysis and manuscript writing. AR contributed to data analysis and manuscript co-writing. LL was involved in TAVI and manuscript correction. PR was involved in echocardiography and manuscript correction. CC was involved in patient selection and echocardiography and manuscript correction. RR was involved in patient selection. PDS was involved in TAVI. SL was involved in data analysis and statistics and manuscript correction.

\section{Competing interests None declared.}

Ethics approval Investigation research centre.

Provenance and peer review Not commissioned; externally peer reviewed.

Open Access This is an Open Access article distributed in accordance with the Creative Commons Attribution Non Commercial (CC BY-NC 4.0) license, which permits others to distribute, remix, adapt, build upon this work noncommercially, and license their derivative works on different terms, provided the original work is properly cited and the use is non-commercial. See: http:// creativecommons.org/licenses/by-nc/4.0/

\section{REFERENCES}

1. Jaworski C, Mariani JA, Wheeler G, et al. Cardiac complications of thoracic irradiation. J Am Coll Cardiol 2013;61:2319-28.

2. Boerma M. Experimental radiation-induced heart disease: past, present, and future. Radiat Res 2012;178:1-6.
3. Aleman BM, van den Belt-Dusebout AW, Klokman WJ, et al. Long-term cause-specific mortality of patients treated for Hodgkin's disease. J Clin Oncol 2003;21:3431-9.

4. Swerdlow AJ, Higgins CD, Smith P, et al. Myocardial infarction mortality risk after treatment for Hodgkin disease: a collaborative British cohort study. J Natl Cancer Inst 2007;99:206-14.

5. Ng AK, Bernardo MP, Weller E, et al. Long-term survival and competing causes of death in patients with early-stage Hodgkin's disease treated at age 50 or younger. $J$ Clin Oncol 2002;20:2101-8.

6. Heidenreich PA, Hancock SL, Lee BK, et al. Asymptomatic cardiac disease following mediastinal irradiation. J Am Coll Cardiol 2003;42:743-9.

7. Wethal $\mathrm{T}$, Lund MB, Edvardsen $\mathrm{T}$, et al. Valvular dysfunction and left ventricular changes in Hodgkin's lymphoma survivors. A longitudinal study. Br J Cancer 2009;101:575-81.

8. Hull MC, Morris CG, Pepine CJ, et al. Valvular dysfunction and carotid, subclavian, and coronary artery disease in survivors of Hodgkin lymphoma treated with radiation therapy. JAMA 2003;290:2831-7.

9. Carlson RG, Mayfield WR, Normann S, et al. Radiation-associated valvular disease. Chest 1991;99:538-45.

10. Galper SL, Yu JB, Mauch PM, et al. Clinically significant cardiac disease in patients with Hodgkin lymphoma treated with mediastinal irradiation. Blood 2011;117:412-18.

11. Mittal S, Berko B, Bavaria J, et al. Radiation-induced cardiovascular dysfunction. Am J Cardiol 1996;78:114-15.

12. Leon MB, Smith CR, Mack M, et al. Transcatheter aortic-valve implantation for aortic stenosis in patients who cannot undergo surgery. N Engl J Med 2010;363:1597-607.

13. Zahn R, Schiele R, Gerckens U, et al. Transcatheter aortic valve implantation in patients with "porcelain" aorta (from a Multicenter Real World Registry). Am J Cardiol 2013;111:602-8.

14. Baumgartner $\mathrm{H}$, Hung J, Bermejo J, et al., American Society of Echocardiography; European Association of Echocardiography. Echocardiographic assessment of valve stenosis: EAE/ASE recommendations for clinical practice. J Am Soc Echocardiogr 2009;22:1-23; quiz 101-2.

15. Holmes DR Jr, Mack MJ, Kaul S, et al. 2012 ACCF/AATS/SCAI/STS expert consensus document on transcatheter aortic valve replacement. J Am Coll Cardiol 2012;59:1200-54.

16. Vahanian A, Alfieri O, Andreotti F, et al., ESC Committee for Practice Guidelines (CPG); Joint Task Force on the Management of Valvular Heart Disease of the European Society of Cardiology (ESC); European Association for Cardio-Thoracic Surgery (EACTS). Guidelines on the management of valvular heart disease (version 2012): the Joint Task Force on the Management of Valvular Heart Disease of the European Society of Cardiology (ESC) and the European Association for Cardio-Thoracic Surgery (EACTS). Eur $J$ Cardiothorac Surg 2012;42:S1-44.

17. Roques F, Nashef SA, Michel P; EuroSCORE study group. Risk factors for early mortality after valve surgery in Europe in the 1990s: lessons from the EuroSCORE pilot program. $J$ Heart Valve Dis 2001;10:572-7; discussion 577-8.

18. Ferguson TB Jr, Dziuban SW Jr, Edwards FH, et al. The STS National Database: current changes and challenges for the new millennium. Committee to Establish a National Database in Cardiothoracic Surgery, The Society of Thoracic Surgeons. Ann Thorac Surg 2000;69:680-91.

19. Kappetein AP, Head SJ, Généreux P, et al. Updated standardized endpoint definitions for transcatheter aortic valve implantation: the Valve Academic Research Consortium-2 consensus document. $J$ Thorac Cardiovasc Surg 2013;145:6-23.

20. Gilard M, Eltchaninoff $\mathrm{H}$, lung $\mathrm{B}$, et al. Registry of transcatheter aortic-valve implantation in high-risk patients. $N$ Engl J Med 2012;366:1705-15.

21. Rosenhek R, Binder T, Porenta G, et al. Predictors of outcome in severe, asymptomatic aortic stenosis. N Engl J Med 2000;343:611-17.

22. Lancellotti $P$, Tribouilloy $C$, Hagendorff $A$, et al. European Association of Echocardiography recommendations for the assessment of valvular regurgitation. Part 1: aortic and pulmonary regurgitation (native valve disease). Eur J Echocardiogr 2010;11:223-44.

23. Lancellotti P, Moura L, Pierard LA, et al. European Association of Echocardiography recommendations for the assessment of valvular regurgitation. Part 2: mitral and tricuspid regurgitation (native valve disease). Eur J Echocardiogr 2010;11:307-32.

24. Zoghbi WA, Enriquez-Sarano M, Foster E, et al. Recommendations for evaluation of the severity of native valvular regurgitation with 
two-dimensional and Doppler echocardiography. J Am Soc Echocardiogr 2003;16:777-802.

25. Brand MD, Abadi CA, Aurigemma GP, et al. Radiation-associated valvular heart disease in Hodgkin's disease is associated with characteristic thickening and fibrosis of the aortic-mitral curtain $J$ Heart Valve Dis 2001;10:681-5.

26. Katz NM, Hall AW, Cerqueira MD. Radiation induced valvulitis with late leaflet rupture. Heart 2001;86:E20.

27. Pohjola-Sintonen S, Tötterman KJ, Salmo M, et al. Late cardiac effects of mediastinal radiotherapy in patients with Hodgkin's disease. Cancer 1987;60:31-7.

28. Copeland KA, Hosmane VR, Jurkovitz C, et al. Frequency of severe valvular disease caused by mediastinal radiation among patients undergoing valve surgery in a community-based, regional academic medical center. Clin Cardiol 2013;36:217-21.

29. Haensig M, Lehmkuhl L, Rastan AJ, et al. Aortic valve calcium scoring is a predictor of significant paravalvular aortic insufficiency in transapical-aortic valve implantation. Eur J Cardiothorac Surg 2012; 41:1234-40

30. Leber AW, Kasel M, Ischinger T, et al. Aortic valve calcium score as a predictor for outcome after TAVI using the CoreValve revalving system. Int J Cardiol 2013;166:652-7.

31. Mwipatayi BP, Picardo A, Masilonyane-Jones TV, et al. Incidence and prognosis of vascular complications after transcatheter aortic valve implantation. J Vasc Surg 2013;58: 1028-36. 